\title{
A Brief Overview of Fish Telemetry Studies on Artificial Reefs in Turkey
}

\author{
Didem Göktürk ${ }^{1}$, Tomris Deniz \\ Istanbul University Faculty of Fisheries, Department of Fisheries Technology, \\ Ordu Cad. No: 200 Laleli, 34470 Istanbul, Turkey
}

\begin{abstract}
Artificial reef which is a human made underwater structure are used in fisheries management to provide new habitats, increase number and biomass of depleted fishery resources, restore habitats, prevent from illegal fishery, reduce fishing pressure on the fish stock and possibly decrease deterioration of habitats. Fish telemetry offers a number of advantages to reveal novel information on fish behaviour in aquatic habitats for tracking the movement of species. In terms of artificial reefs applications, telemetry is important for monitoring fish movement. In the present review we aimed to focus on fish telemetry studies performed on artificial reefs in Turkey.
\end{abstract}

Keywords: Fish telemetry, artificial reef, tagging, Turkey

\section{INTRODUCTION}

Marine ecosystems around the world face many threats and stressors. Cook et al., (2013) stated that, basic life history information (including habitat requirements, migratory routes, foraging and reproductive sites, dispersal and home-range characteristics) is fundamental to understanding animals in relation to their environment, and when studied in the context of responses to human activities, provides resource managers and conservationists with practical knowledge to make informed decisions.

Thorstad et al., (2013) defined that fish telemetry following as: "Telemetry is derived from tele, which means remote, and metron, which means measure. Telemetry is a technology that allows data measurements to be made at a distance, and includes widely used technologies such as telephony, radio and computer networks. Fish telemetry in the broadest definition involves all methods used to obtain information on free-ranging fish, such as use of echo sounders, visual observation, animal vocalization, video and electronic tags (Priede, 1988). However, often when the term fish telemetry is used (also termed biotelemetry, or biologging), it refers only to the use of electronic tags such as radio and acoustic transmitters, data storage tags, pop-up satellite archival tags and PIT-tags (Klimley, 2013). 'Use of electronic tags' would be a more precise description of these methods than fish telemetry or biotelemetry, but the term telemetry to refer to these technologies has become commonly used in the scientific literature (Thorstad et al., 2013)". Marking and tagging is a widely used method for studying wild populations. The idea is simply to label a number of objects such as fish. Thus, it can be obtained lots of knowledges about population parameters: densities, mortality rates, recruitment, age and growth, movements, migrations and mixing of stocks, behavioural and physiological studies (telemetry) etc. (Akyol and Ceyhan, 2003).

It is well known that fish biologists have a variety of tools for studying species in the marine environment. There are many handicaps which have to be overcome, such as given the diversity and lack of knowledge related to fish biology and natural history of most species, as well as the difficulties associated with working in large and relatively remote areas. Telemetry techniques have been widely applied to fisheries research in the world since the 1970s, but relatively few studies have been performed in Turkish marine ecosystems. There are limited studies on fish telemetry in Turkey and they are especially focused on marking and tagging. Here we aimed to give an overview of fish telemetry studies on artificial reefs in Turkish marine fisheries research.

The first study on fish telemetry in artificial reefs were conducted by Ulaş et al., (2009) a project related to tag experiments for some fish species in Ürkmez-Gümüldür artificial reef area. 13 individual scorpion fish and 8 individual Brown merge were tagged, after anesthetize, they were released to artificial reef area by SCUBA divers.

${ }^{1}$ Corresponding Author: didemgokturk@gmail.com 


\section{American Research Journal of Agriculture, Volume 1, Issue 4, 2015 ISSN 2378-9018}

Observations were performed with visual census method by SCUBA divers. At the end of visual census method diving, there is no scorpion fish were recorded, whereas fungus was observed on tail of Brown merge. Another work which is not concerned on artificial reefs it can also be given as an example study on fish telemetry performed by Gül et al., (2009) in Turkey. It was reported tagging experiments in tank environment. The researchers tagged for three species such as Diplodus sargus, Diplodus annularis and Serranus scriba fished from trap and observed the effect of tagging on their behaviour in experimental tanks during eight weeks. Following years residency, home range, and habitat utilization of Scieana umbra, Scorpaena porcus and Scorpaena scrofa in artificial reefs using acoustic telemetry were studied by Özgül et al., (2013). In this study passive acoustic telemetry system (VemcoVR2W) was used to monitor home range, movement patterns and residence time of three fish species (S. umbra, $S$. scrofa and $S$. porcus) in artificial reef area. 3 adult S. porcus (19-27 cm TL), 2 adult $S$. scrofa $(36-44 \mathrm{~cm} \mathrm{TL})$ and 4 individual S. umbra (13-32 cm TL) were surgically fitted with small acoustic transmitters (Vemco V9-2H and V82L) and tracked with Vemco Positioning System (VPS) up to 720 h during various, 24-h periods between August and September 2013 within the Atınoluk Artificial Reef Area, the northern Aegean Sea. Many fish were present near the artificial reefs during the study and demonstrated strong residency and high individual detection rates. They found that within the study area, S. umbra, S. scrofa and S. porcus showed distinct habitat selectivity. The influence of artificial reefs using with ultrasonic telemetry for management of artificial reef sites in coastal zone were also determined by Özgül and Lök (2014). Lök and Özgül (2015), were carried out a study entitled by "Movements of Pomatamus saltatrix in artificial reef area: preliminary results" and they reported that five bluefish (mean length: $29.72 \mathrm{~cm}$, mean weight: $217.80 \mathrm{~g}$ ) were tagged with acoustic transmitters (V9-2H continues transmitter) and released to artificial reef area where captured with line fishing. Bluefishes were monitored by hydrophones (V110 and V165) between 11 February and 27 March 2014. They observed that bluefish preferred artificial reef area between 15 and $32 \mathrm{~m}$ depth and sometimes up to $50 \mathrm{~m}$ depth during day time. But, they preferred move to very shallow areas, especially to stream mouth during night time. They concluded that active telemetry system can be used for determines fish movements around artificial reef areas and contributes for management of the artificial reef areas. Özgül, (2015) was reported a study on "Determining movement patterns of fish to manage of fisheries on artificial reefs". In this study it was used biotelemetry for 57 fish inhabiting either artificial reef site were tagged and monitored their behaviour for up to two years intermittently. In total, 15 Sciaena umbra, 21 Sparid, 14 Scorpanea porcus, 7 Scorpaena scrofa were surgically tagged with acoustic transmitters. Vemco Positioning System (VPS), for 24-h periods, within the Altnoluk Artificial Reef Site in the Northern Aegean Sea, were used for quantify the movement behaviour of these species.

Nowadays, apart from artificial reefs, it is worthy of note that one of the most important studies related to fish telemetry have been conducted by Turkish Marine Research Foundation (TÜDAV) since 2012 on fish tagging with the project name "Where are the bonito?" which is aimed to provide new information, scientifically data for contributing to sustainable management of the Bonito Fisheries, and also to inform not only fishermen but consumers as well (Öztürk and Karakaş, 2012). Presently the results of this three-year study on Bonito (Sarda sarda, Bloch, 1793) are expected.

\section{CONCLUSION}

Artificial reefs have the power to attract the marine life by offering a habitat. Therefore artificial reefs have a great importance extensively around the world for the marine ecosystems. This mini review addresses information on fish telemetry studies on artificial reefs in Turkey. The artificial reef studies which were conducted by using telemetry methods are favourable in order to determine the effectiveness of artificial reefs and identify the use of artificial reefs by fish species.

\section{REFERENCES}

[1] Akyol, O., Ceyhan, T., 2003. Materials and methods which are used in marking and tagging experiments in fishery research. E.U. Journal of Fisheries \& Aquatic Sciences, 20 (1-2): 273-285.

[2] Cooke, S.J., Midwood, J.D., Thiem, J.D., Klimley, P., Lucas, M.C., Thorstad, E.B., Eiler, J., Holbrook, C., Ebner, B.C., 2013. Tracking animals in freshwater with electronic tags: past, present and future. Animal Biotelemetry 2013, 1:5.

[3] Gül, B., Sönmez, E., Lök, A., The tagging experiment in tank environment. p. 478-491, XV. National Aquatic Sciences Symposium. 01-04 Temmuz 2009, Rize, Turkey (in Turkish).

[4] Klimley, A.P. 2013. Why publish in Animal Biotelemetry? Animal Biotelemetry, 1:1. 


\section{American Research Journal of Agriculture, Volume 1, Issue 4, 2015}

ISSN 2378-9018

[5] Lök, A., Özgül, A., 2015. Movements of Pomatamus saltatrix in artificial reef area: preliminary results. 3rd International Conference on Fish Telemetry Abstract Book, p 15, 13-17 July 2015, Halifax, Nova Scotia, Canada.

[6] Özgül, A., Lök,A., Ulaş, A., Düzbastılar, F.O., Tanrıkulu, T.T., Pelister, C., 2013. Residency, home range, and habitat utilization of Scieana umbra, Scorpaena porcus and Scorpaena scrofa in artificial reefs using acoustic telemetry. 10th CARAH - International Conference on Artificial Reefs and Related Aquatic Habitats, September 23-27, Ege University, İzmir Turkey.

[7] Özgül, A., Lök, A., 2014. To determine influence of artificial reefs using with ultrasonic telemetry for management of artificial reef sites in coastal zone. The Third International Symposium on Integrated Coastal Zone Management, October 14-17, 2014, Belek, Antalya, Turkey.

[8] Özgül, A., 2015. Determining movement patterns of fish to manage of fisheries on artificial reefs. 3rd International Conference on Fish Telemetry Abstract Book, p 21, 13-17 July 2015, Halifax, Nova Scotia, Canada.

[9] Öztürk, B., Karakaş, E., 2012. Where are the bonito? p. 171. In: Underwater science and technology meeting 2012, Istanbul Faculty of Medicine, 17-18 November 2012. Istanbul University, Istanbul.

[10] Priede, I.G. 1988. Wildlife Telemetry: an introduction. In Wildlife Telemetry. Remote monitoring and tracking animals (Priede, I.G. and Swift, S.M., eds). Ellis Horwood Ltd.

[11] Thorstad, E.B., Rikardsen, A.H., Alp A., Økland, F., 2013. The Use of Electronic Tags in Fish Research - An Overview of Fish Telemetry Methods. Turkish Journal of Fisheries and Aquatic Sciences 13: 881-896 (2013).

[12] Ulaş, A., Lök, A., Metin, C., Düzbastılar, F.O., Özgül, A., Gül, B., Başaran, F., Duman, Ü., 2009. Tag Experiment on Some Fish Species in Artificial Reef. Ege University project number: 2008/SAUM/001, İzmir, Turkey, 36pp (in Turkish). 